\title{
Femoral Component Positioning in Hip Resurfacing With and Without Navigation
}

\author{
Muthu Ganapathi MSc, FRCS(Orth), \\ Pascal-André Vendittoli MD, MSc, FRCS(C), \\ Martin Lavigne MD, FRCS(C), Klaus-Peter Günther
}

Received: 15 October 2007/ Accepted: 29 April 2008/Published online: 17 May 2008

(C) The Association of Bone and Joint Surgeons 2008

\begin{abstract}
Early failures after hip resurfacing often are the result of technical errors in placing the femoral component. We asked whether image-free computer navigation decreased the number of outliers compared with the conventional nonnavigated technique. We retrospectively compared 51 consecutive hip resurfacings performed using image-free computer navigation with 88 consecutive hip resurfacings performed without navigation. Patient demographics were similar. There were no differences in the average native femoral neck-shaft angles, planned stemshaft angles, or postoperative stem-shaft angles. However, when the postoperative stem-shaft angle was compared with the planned stem-shaft angle, there were 33 patients $(38 \%)$ in the nonnavigated group with a deviation greater than $5^{\circ}$ in contrast to none in the navigated group. Notching was present in four patients in the nonnavigated group and none in the navigated group. The average
\end{abstract}

One or more of the authors (P-AV, ML) has received funding from Zimmer, Warsaw for the design of the Orthosoft navigation software for Durom hip resurfacing.

Each author certifies that his or her institution has approved the human protocol for this investigation, that all investigations were conducted in conformity with ethical principles of research, and that informed consent for participation in the study was obtained.

M. Ganapathi

Maisonneuve-Rosemont Hospital, Montreal, QC, Canada

P.-A. Vendittoli ( $₫)$, M. Lavigne

Department of Surgery, Montreal University,

Maisonneuve-Rosemont Hospital, 5415 Boul L'Assomption,

Montreal, QC, Canada H1T 2M4

e-mail: pa.vendittoli@videotron.ca

K.-P. Günther

Department of Orthopaedics, Dresden University, Dresden, Germany operative time was 111 minutes for the navigated group and 105 minutes for the nonnavigated group. Image-free navigation decreased the number of patients with potentially undesirable implant placements.

Level of Evidence: Level III, therapeutic study. See the Guidelines for Authors for a complete description of levels of evidence.

\section{Introduction}

Hip resurfacing (HR) is being offered more frequently as a more bone-conserving option for young, active patients with hip arthritis. However, it is a technically more demanding procedure than conventional THA with a substantial learning curve. Patients considered for HR often have considerable variation in the femoral head-neck anatomy and this may pose a major challenge to the surgeon when preparing the femoral head [11, 24]. Intraoperative technical errors during femoral preparation are important reasons for short-term and midterm failures of the procedure $[6,8,23]$.

Femoral neck notching has been associated with early femoral neck fractures $[2,23]$. An increased failure rate also has been associated with varus position of the femoral component (less than $130^{\circ}$ ) as measured on plain radiographs [6]. However, too much valgus may result in notching.

Any intraoperative aid that allows the surgeon to reliably place the femoral component in the planned angle may be helpful. Recent cadaveric and sawbone studies suggest using navigation for HR is more accurate [14, 26]. Similar conclusions have been reported in smaller clinical studies using fluoroscopic guidance or fluoroscopic-based surgical navigation $[7,17,20]$. 
We asked four questions: (1) whether navigation would reduce outliers; (2) whether navigation would reduce the differences in planned and actual (postoperative) stemshaft angles; (3) whether navigation would increase operative time and blood loss; and (4) whether navigation would reduce notching.

\section{Materials and Methods}

We retrospectively compared two sequential groups of patients undergoing hip resurfacing. The patients in the nonnavigated group were operated on in the earlier part of the study (during a 12-month period), whereas the navigated group consisted of patients operated on during the subsequent 17 months (there also were some nonnavigated HRs performed during this latter period owing to the limitation of available instrumentation for navigation, but these were not included in the study cohort). Thus we performed $139 \mathrm{HR}$ procedures in 125 patients (14 bilateral cases with staged surgery). There were 51 hips in the navigated group and 88 hips in the nonnavigated group (Table 1).

We considered femoral components with postoperative stem-shaft angles greater than $5^{\circ}$ from the planned stemshaft angle as outliers. In the nonnavigated group, there were $33(38 \%)$ outliers. With a power of $80 \%$ and an alpha error of 0.05 , we estimated 52 cases were required in the navigated group to show a reduction of $66 \%$. There were no differences in gender, age, height, weight, body mass index, or component size between the two groups (Table 1). The number of patients included in the study by the two participating surgeons differed $(\mathrm{p}=0.05)$, with 26 navigated and 30 nonnavigated for $\mathrm{K}-\mathrm{PG}$ and 25 navigated and 58 nonnavigated for $\mathrm{P}-\mathrm{AV}$.

Both surgeons (K-PG, P-AV) had performed more than 75 HRs using the conventional technique before the current study and therefore we presumed would be over the learning curve for conventional HR. The navigated group included all patients who had undergone navigated HR by both surgeons when they began performing navigated HR, and thus these patients would be within the learning curve for the navigated technique. The Durom HR components (Zimmer, Warsaw, IN) were implanted in all patients using a posterior approach. In the nonnavigated group, the alignment device provided by the manufacturer was used. This device allows for independent translation in superoinferior and anteroposterior directions and the possibility to change the angular orientation independently (Figs. 1, 2). In the navigated group, the Navitrack system (Zimmer CTFree 1.0 navigation system software; Orthosoft, Montreal, Canada) specifically adapted for the Durom HR system was used. In this navigation system, passive infrared diodes are used for image capturing and allow anatomic threedimensional reconstruction of the proximal femur. The software provides an option for selecting the femoral

Table 1. Patient demographics and radiographic measurements

\begin{tabular}{|c|c|c|c|}
\hline Demographics and measurements & Navigated (SD; range) & Nonnavigated (SD; range) & $\mathrm{p}$ Value \\
\hline Number of hips & 51 & 88 & \\
\hline \multicolumn{4}{|l|}{ Gender } \\
\hline Male & $70.6 \%(\mathrm{n}=36)$ & $68.2 \%(\mathrm{n}=60)$ & \\
\hline Female & $29.4 \%(\mathrm{n}=15)$ & $31.8 \%(\mathrm{n}=28)$ & \\
\hline Mean age (years) & $48(8.8 ;$ range, $18-64)$ & 48 (9.6; range, 16-77) & 0.949 \\
\hline Average height (meters) & 1.73 (0.09); range, 1.52-1.91) & $1.73(0.08 ;$ range, $1.52-1.95)$ & 0.801 \\
\hline Average weight $(\mathrm{kg})$ & $79.3(12.8 ;$ range, 56-104) & $82(18.3 ;$ range, $48-140)$ & 0.346 \\
\hline Body mass index $\left(\mathrm{kg} / \mathrm{m}^{2}\right)$ & $26.5(3.2 ;$ range, $18.2-32.5)$ & $27(5.2 ;$ range, $17.6-43.7)$ & 0.210 \\
\hline Blood loss (mL) & 445 (182; range, 200-1000) & 516 (296; range, 100-1600) & 0.118 \\
\hline Femoral component diameter $(\mathrm{mm})$ & 49 (3.5; range, 40-56) & 49 (4.1; range, 42-60) & 0.539 \\
\hline Operative time (minutes) & 111 (16.1; range, 80-150) & 105 (17.0; range, 60-185) & 0.048 \\
\hline Native femoral neck shaft angle (degrees) & 132 (7.3; range, 120-153) & 131 (5.8; range, 116-144) & 0.284 \\
\hline Planned neck-shaft angle (degrees) & 138 (4.1; range, 131-152) & 137(3.4; range, 128-146) & 0.055 \\
\hline Postoperative stem-shaft angle (degrees) & 139 (4.5; range, 130-152) & 139 (5.9; range, 127-155) & 0.719 \\
\hline $\begin{array}{l}\text { Difference between postoperative stem-shaft } \\
\text { angle and native neck-shaft angle (degrees) }\end{array}$ & $6.3(4.5,-6.0-18.0)$ & $7.8(0.7 ;$ range, $-7.0-2.0)$ & 0.129 \\
\hline $\begin{array}{l}\text { Mean postoperative stem-shaft angle } \\
\text { minus planned stem-shaft angle (degrees) }\end{array}$ & $0.4(1.6 ;$ range, $-4.0-3.0)$ & $2.1(5.3$; range, $-8.0-16.0)$ & 0.005 \\
\hline $\begin{array}{l}\text { Mean absolute postoperative neck-shaft angle } \\
\text { minus planned neck-shaft angle (degrees) }\end{array}$ & $1.3(0.9 ;$ range, $0-4)$ & 4.4 (3.6; range, $0-16)$ & $\leq 0.001$ \\
\hline
\end{tabular}




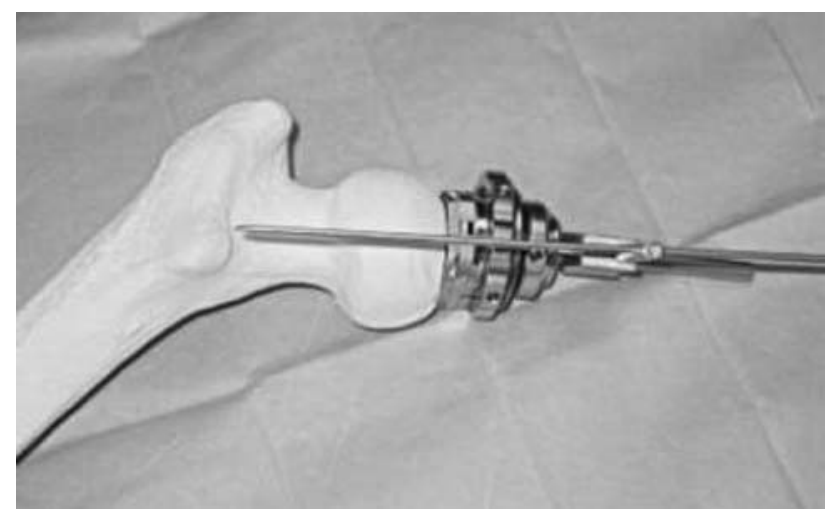

Fig. 1 A conventional Durom jig is shown with the alignment guide wire.

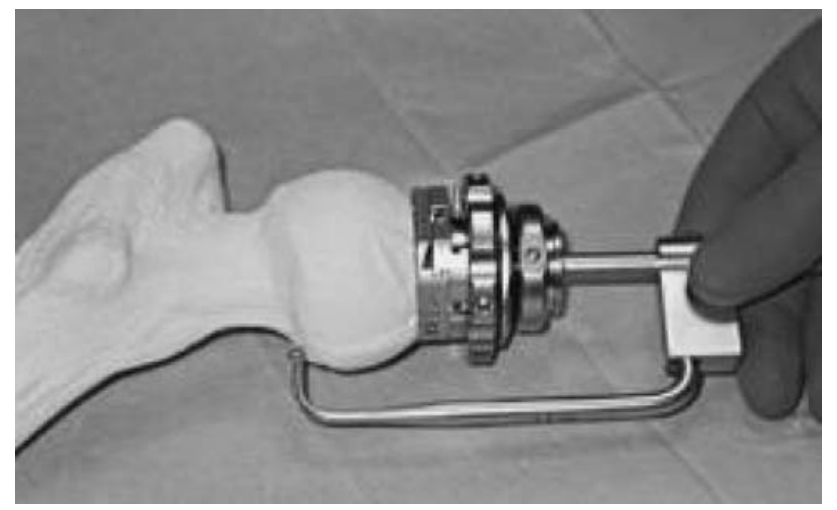

Fig. 2 A conventional Durom jig is shown with the notch-checking device.

component size, angulation, and translation relative to the femoral neck. A notch-detecting tool also is available. Navigation was performed only for the femoral component. During femoral head preparation, a femoral tracker was secured with pins in the posterior greater trochanter with two 3.3-mm-diameter threaded pins. The morphologic features of the proximal femur were reconstructed by the software after registration of the following landmarks with a 2-mm pointer: the midpoint of the superior part of the femoral neck, medial and lateral femoral epicondyles, medial and lateral malleolus, and femoral neck (minimum of 275 points) and head surface (minimum of 50 points per quadrant). The surgeon then could select the implant size and fine-tune anteversion/retroversion, varus/valgus, and translation to optimize the final guide wire position, which provides adequate bone support and avoid notching.

All radiographic measurements were taken from standardized anteroposterior radiographs of the pelvis (taken with the foot in $15^{\circ}$ internal rotation). The contralateral hip was used for measurement if there was external rotation contracture. The native neck-shaft angles and the postoperative stem-shaft angles were measured from preoperative and early postoperative anteroposterior radiographs of the pelvis by one independent observer (MG) blinded to the surgical technique. The neck-shaft angle was defined by a line drawn along the center of the femoral shaft and a line drawn along the center of the femoral neck. The stem-shaft angle was defined by a line drawn along the center of the femoral shaft and a line drawn along the center of the stem of the femoral component. The stem-shaft angle, templated by the respective surgeons (K-PG, P-AV) from the preoperative radiograph, was considered the planned stem-shaft angle for the nonnavigated cases. For the navigated cases, the intraoperative stem-shaft angle accepted before inserting the guide wire was considered the planned stem-shaft angle. The planned neck-shaft angle selected by the surgeons during radiographic templating and navigating was based on their clinical judgment and experience. Presence or absence of notching also was recorded for both groups at the end of the surgery.

The proportion of outliers was compared between groups with the chi square test. All continuous variables showed equal variance with Levene's test for equality of variance. Mean differences between postoperative position and planned position, postoperative position for each group, and difference of error for each group were evaluated by Student's t-test for equal variances. Analysis was performed using the Statistical Package for the Social Sciences (SPSS ® 15.0 software; SPSS Inc., Chicago, IL).

\section{Results}

More patients ( $\mathrm{p} \leq 0.001)$ in the nonnavigated group had a postoperative stem-shaft angle greater than $5^{\circ}$ deviation from the planned neck-shaft angle compared with the navigated group (33 of 88 [38\%] versus none of 51) (Table 2). More patients $(\mathrm{p} \leq 0.001)$ in the nonnavigated group also had a postoperative stem-shaft angle deviation greater than $3^{\circ}$ from the planned stem-shaft angle than in the navigated group (50 of 88 [57\%] versus four of 51 or $8 \%$ ). We observed no differences between the two groups in the native neck-shaft angles, the planned stem-shaft angles (Table 1), or the mean postoperative stem-shaft angles (Fig. 3).

Table 2. Deviation of postoperative stem-shaft angle from planned stem-shaft angle

\begin{tabular}{llll}
\hline Deviation & $\begin{array}{l}\text { Navigated } \\
\text { (Number) }\end{array}$ & $\begin{array}{l}\text { Nonnavigated } \\
\text { (Number) }\end{array}$ & $\mathrm{p}$ Value \\
\hline Greater than $5^{\circ}$ & $0(0 \%)$ & $33(38 \%)$ & $\leq 0.0001$ \\
Greater than $3^{\circ}$ & $4(8 \%)$ & $50(57 \%)$ & $\leq 0.0001$ \\
\hline
\end{tabular}




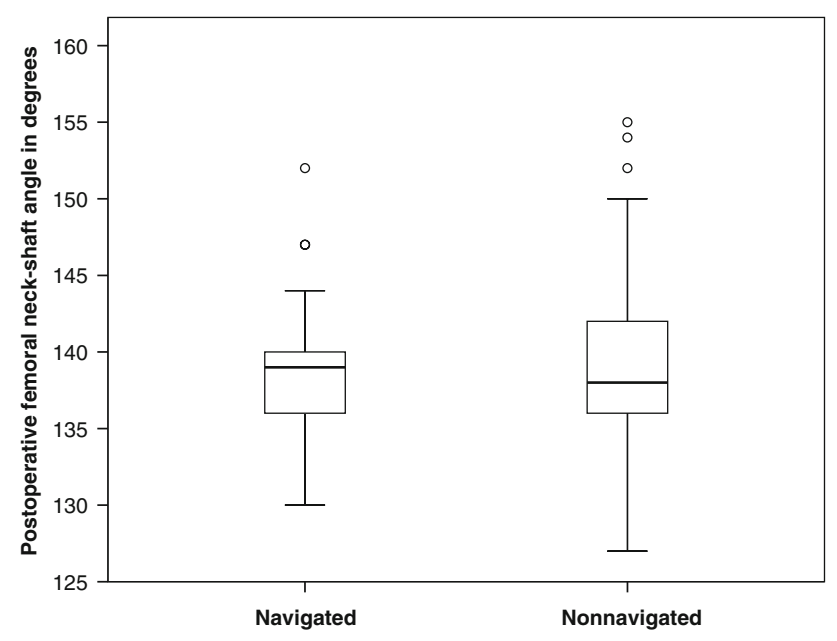

Fig. 3 A box plot shows the postoperative stem-shaft angles for the navigated and nonnavigated groups. Box lengths represent the interquartile range (first to third quartiles). The line in the center of the boxes represents the median value. Data represented by "o" are outliers (greater than 1.5 to 3.0 times the interquartile range over the third quartile) and data represented by the asterisks are extreme values (greater than three times the interquartile range over the third quartile)

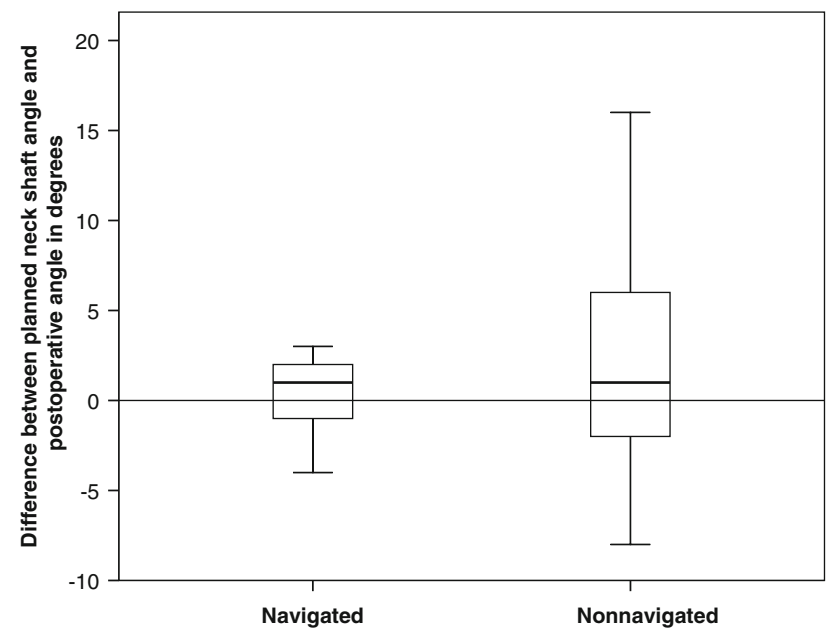

Fig. 4 The box plot shows the difference between the planned stemshaft angle and the postoperative stem-shaft angle for the navigated and nonnavigated groups. Box lengths represent the interquartile range (first to third quartiles). The line in the center of the boxes represents the median value. Data represented by "o" are outliers (greater than 1.5 to 3.0 times the interquartile range over the third quartile) and data represented by the asterisks are extreme values (greater than three times the interquartile range over the third quartile).

The mean differences in the planned and the postoperative stem-shaft angles were greater $(p=0.005)$ in the nonnavigated group than in the navigated group (mean differences of $2.1^{\circ}$ versus $0.4^{\circ}$ respectively) (Fig. 4). The nonnavigated technique had a bias toward placing the femoral component in excessive valgus when compared with the navigation technique that had no bias for valgus and varus placement: the mean difference between the planned and postoperative neck-shaft angles for the nonnavigated group was different from zero $(p=0.0004)$, whereas for the navigated group, it did not differ from zero $(\mathrm{p}=0.1202)$. There was greater $\left(4.4^{\circ}\right.$ vs $\left.1.3^{\circ}, \mathrm{p} \leq 0.01\right)$ absolute error (postoperative stem-shaft angle minus planned stem-shaft angle) in the nonnavigated group with a maximum error of $16^{\circ}$ compared with a maximum error of $4^{\circ}$ in the navigated group (Fig. 5). There was more scatter $(\mathrm{p} \leq 0.01)$ in the difference between the postoperative stem-shaft angle and the planned stem-shaft angle in the nonnavigated group (standard deviation, $3.6^{\circ}$ ) when compared with the navigated group (standard deviation, $0.9^{\circ}$ ) (Fig. 6). For a given patient with a target angle set, it was estimated the positioning precision using navigation was $1.3^{\circ} \pm 0.9^{\circ}$ compared with $4.4^{\circ} \pm 3.6^{\circ}$ without navigation $(\mathrm{p}<0.0001)$.

Operative time was greater $(\mathrm{p}=0.048)$ for the navigated group compared with the nonnavigated group (111 minutes versus 105 minutes); we observed no difference in blood loss (Table 1). However, when analyzing separately for each surgeon, one surgeon had increased $(p=0.011)$ operative time for the navigated group (116 minutes versus 108 minutes), whereas the other surgeon had no difference $(\mathrm{p}=0.860)$ (103 minutes for the navigated group versus 104 minutes for the nonnavigated group).

There were more patients $(\mathrm{p}=0.122)$ with notching ( $2 \mathrm{~mm}$ or less) in the noncritical area (anterior or posterior) in the nonnavigated group (four of 88 patients versus none

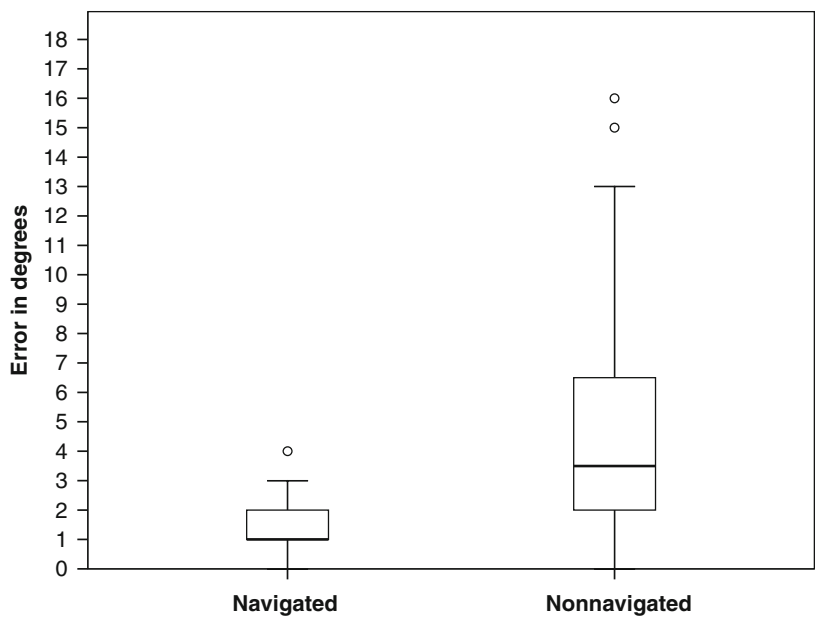

Fig. 5 The box plot shows the absolute error (difference) between the postoperative stem-shaft angle and the planned stem-shaft angle for the navigated and nonnavigated groups. Box lengths represent the interquartile range (first to third quartiles). The line in the center of the boxes represents the median value. Data represented by "o" are outliers (greater than 1.5 to 3.0 times the interquartile range over the third quartile) and data represented by the asterisks are extreme values (greater than three times the interquartile range over the third quartile). 


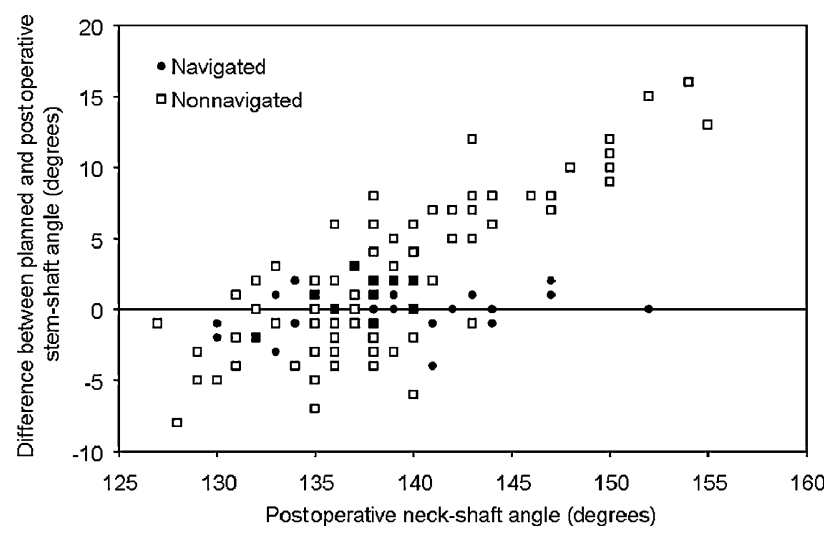

Fig. 6 The error (postoperative stem-shaft angle minus planned stem-shaft angle) for each postoperative stem-shaft angle achieved in the navigated and nonnavigated groups is shown.

of 51). No other intraoperative technical problem was encountered in either of the groups. There were no postoperative femoral neck fractures.

\section{Discussion}

Earlier generations of HR had a high failure rate resulting from severe polyethylene wear, improper implant design, limited sizes, and poor instrumentation [8, 18, 19, 22]. With modern metal-on-metal articulation, many of the early failures have been related to technical errors in placement of the femoral component $[1,2,5,6,23]$. We asked four questions: (1) whether navigation would reduce outliers; (2) whether navigation would reduce differences in planned and actual (postoperative) stem-shaft angles; (3) whether navigation would increase operative time and blood loss; and (4) whether navigation would reduce notching.

Our study has some limitations. First, our measurements were made on plain radiographs. We accept the native neck-shaft angles and stem-shaft angles could be affected by rotation of the femur and computed tomographic (CT) scan measurement would have been the better method. However, because of the retrospective nature of the study, this was not possible. We have tried to minimize the error by using standardized radiographs and using the contralateral hip for measurement if required. In addition, all the studies that have analyzed femoral component alignment in relevance to the complications have used plain radiographs for analysis, and therefore our measurements are clinically relevant $[6,8,23]$. Second, all measurements were made only once by an independent observer. therefore, we do not have measures of intraobserver or interobserver reliability. However, the same technique was used throughout. Although it could be argued that because the planned stem-shaft angle for the nonnavigated technique was based on the plain radiographs and therefore there may be an error in the planning, there were no differences between the groups regarding either the measured native neck-shaft angle or the planned stem-shaft angle. The error also was spread in varus and valgus directions. Notching also was avoided in the navigated group. Finally, we recognize a randomized clinical trial would have been ideal to study the value of navigation in HR. Despite these limitations, we believe our results are valid. There were no considerable differences in the patients' demographics, and the number of cases was large. The radiographic results also were similar for the two surgeons operating independently of each other. Navigation was more precise despite the inclusion of patients in the learning curve for that technique. Both surgeons had performed more than 75 HRs using the conventional technique predating the study cohort.

Varus positioning of the femoral component has been implicated as a risk factor for femoral neck fractures after HR. A study analyzing 50 femoral neck fractures after HR found $71.1 \%$ of patients showed greater than $5^{\circ}$ varus placement of the femoral component when compared with the preoperative femoral neck-shaft angle [23]. Moreover, notching was present in $46.6 \%$ of the cases. No fracture occurred when the femoral component was positioned in valgus compared with the preoperative neck-shaft angle. Another study of failures after HR showed the mean stemshaft angle was $139^{\circ}$ for hips without problems versus $133^{\circ}$ for hips with problems $[5,6]$. Hips with a $130^{\circ}$ or less stem-shaft angle had an increase in the relative risk of an adverse outcome.

Although there is general consensus to avoid varus positioning of the femoral component, there is no consensus regarding the amount of valgus required. Although Freeman [15] suggested the femoral component should be placed at a $20^{\circ}$ angle to the vertical, Amstutz et al. suggested reaming at a $140^{\circ}$ angle [2]. A recent biomechanical study of paired cadaveric femora suggested improvement in fracture load was achieved with a valgus position of $10^{\circ}$ in the specimens with relatively low neck-shaft angles $\left(128^{\circ}-132^{\circ}\right)$ [3]. In the specimens with an average neckshaft angle of $133^{\circ}$ to $139^{\circ}$, the authors reported little benefit to increasing valgus. They also found a larger size component was required (to avoid notching) if the guide wire was placed in greater than $20^{\circ}$ relative valgus. During preoperative planning, both surgeons (K-PG, P-AV) aimed to place the femoral component in slight valgus compared with the native neck-shaft angle.

Hip resurfacing is technically more challenging than conventional THA and is associated with a steep learning curve. In a study using sawbones, even medical students were more accurate in placing the guide wire in the proper position during HR when navigation was used (mean error 
$7^{\circ}$ ) compared with either conventional instrumentation alone (mean error $23^{\circ}$ ) or conventional instrumentation with additional planning from $\mathrm{CT}$ images (mean error $22^{\circ}$ ) [13]. A cadaveric study also found, when aiming for a predetermined stem-shaft angle of $135^{\circ}$, the mean stemshaft angle obtained by conventional instrumentation was $127.7^{\circ}$ (range, $120^{\circ}-132^{\circ}$ ) compared with $133.3^{\circ}$ (range, $131^{\circ}-139^{\circ}$ ) in the computer navigation group [14]. Accuracy of guide wire placement also has been improved by using either fluoroscopic guidance [26] or fluoroscopicbased surgical navigation [7, 17].

Our data suggest computer navigation allows more reproducible placement of the femoral component in the coronal plane during $\mathrm{HR}$ as measured on plain radiographs when compared with conventional instrumentation $(0 \%$ versus $38 \%$ of the cases with and without navigation had a postoperative neck-shaft angle that deviated greater than $5^{\circ}$ when compared with the planned neck-shaft angle; $p$ $\leq 0.001)$. The scatter also was considerably narrower in the navigated group (standard deviations of $0.9^{\circ}$ and $3.6^{\circ}$ for the navigated and nonnavigated groups, respectively, for the difference between the postoperative stem-shaft angle and the planned stem-shaft angle). Much variation in the postoperative stem-shaft angle also has been reported by others using the conventional technique for HR $\left(117^{\circ}-\right.$ $156^{\circ}$ ) [6]. There was no notching in the navigated group compared with four in the nonnavigated group. The operative time was greater by only 8 minutes in the navigated group for one surgeon, whereas there was no considerable difference between the groups for the other surgeon.

Although navigation provides accurate positioning of the component in TKA [10,12, 16, 21, 25], no long-term studies provide evidence navigation either decreases the rate of revisions or extends the durability of TKAs [4, 9]. However, with HR, there is conclusive evidence component malpositioning is a major factor associated with adverse outcome, even in the short term [6, 23]. Hip resurfacing often is performed in young, active patients who put more demand on their hip prostheses. In light of this, the value of navigating the femoral component during HR is reinforced, especially in a procedure with a steep learning curve. Additional knowledge and consensus regarding the optimal value of valgus positioning would allow the surgeon to make a precise judgment for guide wire placement with the aid of computer navigation.

\section{References}

1. Amstutz HC, Beaule PE, Dorey FJ, Le Duff MJ, Campbell PA, Gruen TA. Metal-on-metal hybrid surface arthroplasty: two to six-year follow-up study. J Bone Joint Surg Am. 2004;86:28-39.
2. Amstutz HC, Campbell PA, Le Duff MJ. Fracture of the neck of the femur after surface arthroplasty of the hip. J Bone Joint Surg Am. 2004;86:1874-1877.

3. Anglin C, Masri BA, Tonetti J, Hodgson AJ, Greidanus NV. Hip resurfacing femoral neck fracture influenced by valgus placement. Clin Orthop Relat Res. 2007;465:71-79.

4. Bauwens K, Matthes G, Wich M, Gebhard F, Hanson B, Ekkernkamp A, Stengel D. Navigated total knee replacement: a meta-analysis. J Bone Joint Surg Am. 2007;89:261-269.

5. Beaule PE, Dorey FJ, LeDuff M, Gruen T, Amstutz HC. Risk factors affecting outcome of metal-on-metal surface arthroplasty of the hip. Clin Orthop Relat Res. 2004;418:87-93.

6. Beaule PE, Lee JL, Le Duff MJ, Amstutz HC, Ebramzadeh E. Orientation of the femoral component in surface arthroplasty of the hip: a biomechanical and clinical analysis. J Bone Joint Surg Am. 2004;86:2015-2021.

7. Belei P, Skwara A, De La Fuente M, Schkommodau E, Fuchs S, Wirtz DC, Kamper C, Radermacher K. Fluoroscopic navigation system for hip surface replacement. Comput Aided Surg. 2007;12: $160-167$.

8. Bell RS, Schatzker J, Fornasier VL, Goodman SB. A study of implant failure in the Wagner resurfacing arthroplasty. $J$ Bone Joint Surg Am. 1985;67:1165-1175.

9. Beringer DC, Patel JJ, Bozic KJ. An overview of economic issues in computer-assisted total joint arthroplasty. Clin Orthop Relat Res. 2007;463:26-30.

10. Bolognesi M, Hofmann A. Computer navigation versus standard instrumentation for TKA: a single-surgeon experience. Clin Orthop Relat Res. 2005;440:162-169.

11. Boyd HS, Ulrich SD, Seyler TM, Marulanda GA, Mont MA. Resurfacing for Perthes disease: an alternative to standard hip arthroplasty. Clin Orthop Relat Res. 2007;465:80-85.

12. Chin PL, Yang KY, Yeo SJ, Lo NN. Randomized control trial comparing radiographic total knee arthroplasty implant placement using computer navigation versus conventional technique. J Arthroplasty. 2005;20:618-626.

13. Cobb JP, Kannan V, Brust K, Thevendran G. Navigation reduces the learning curve in resurfacing total hip arthroplasty. Clin Orthop Relat Res. 2007;463:90-97.

14. Davis ET, Gallie P, Macgroarty K, Waddell JP, Schemitsch E. The accuracy of image-free computer navigation in the placement of the femoral component of the Birmingham Hip Resurfacing: a cadaver study. J Bone Joint Surg Br. 2007;89:557-560.

15. Freeman MA. Some anatomical and mechanical considerations relevant to the surface replacement of the femoral head. Clin Orthop Relat Res. 1978;134:19-24.

16. Haaker RG, Stockheim M, Kamp M, Proff G, Breitenfelder J, Ottersbach A. Computer-assisted navigation increases precision of component placement in total knee arthroplasty. Clin Orthop Relat Res. 2005;433:152-159.

17. Hess T, Gampe T, Kottgen C, Szawlowski B. [Intraoperative navigation for hip resurfacing: methods and first results][in German]. Orthopade. 2004;33:1183-1193.

18. Howie DW, Campbell D, McGee M, Cornish BL. Wagner resurfacing hip arthroplasty: the results of one hundred consecutive arthroplasties after eight to ten years. J Bone Joint Surg Am. 1990;72:708-714.

19. Howie DW, Cornish BL, Vernon-Roberts B. Resurfacing hip arthroplasty: classification of loosening and the role of prosthesis wear particles. Clin Orthop Relat Res. 1990;255:144-159.

20. Kruger S, Zambelli PY, Leyvraz PF, Jolles BM. Computerassisted placement technique in hip resurfacing arthroplasty: improvement in accuracy? Int Orthop. Aug 242007 [Epub ahead of print]. 
21. Picard F, Deakin AH, Clarke JV, Dillon JM, Gregori A. Using navigation intraoperative measurements narrows range of outcomes in TKA. Clin Orthop Relat Res. 2007;463:50-57.

22. Ritter MA, Gioe TJ. Conventional versus resurfacing total hip arthroplasty: a long-term prospective study of concomitant bilateral implantation of prostheses. J Bone Joint Surg Am. 1986;68:216-225.

23. Shimmin AJ, Back D. Femoral neck fractures following Birmingham hip resurfacing: a national review of 50 cases. J Bone Joint Surg Br. 2005;87:463-464.
24. Vendittoli PA, Lavigne M, Roy AG, Girard J. Removal of acetabular bone in resurfacing arthroplasty of the hip. J Bone Joint Surg Br. 2006;88:838-839.

25. Victor J, Hoste D. Image-based computer-assisted total knee arthroplasty leads to lower variability in coronal alignment. Clin Orthop Relat Res. 2004;428:131-139.

26. Wirth CJ, Gosse F. Improved implantation technique for resurfacing arthroplasty of the hip. Oper Orthop Traumatol. 2006;18: 214-224. 